\title{
Possible Measures Electromagnetic Waves Generated by Diamagnetic Currents Produced in the lonosphere by High-Frequency (HF)
}

\author{
Inácio M. Martin, Alessandro J. de Abreu, Douglas C. Vilela, Marcelo P. Gomes, Mauro A. Alves and Rodrigo R. \\ F. Carvalho \\ Physics Department, Aeronautical Technological Institute-ITA, São José dos Campos, SP 12228-900, Brazil
}

\begin{abstract}
In a recent article the authors described a possible process of generating electromagnetic waves in the range of 1-12 $\mathrm{Hz}$ caused by diamagnetic currents originated by heat in ionosphere by high frequency waves (HF). The origin of the HF waves that reach the ionosphere can be sent from the Earth's surface (HAARP- High Frequency Active Auroral Research Program) or even solar. Through a SpectranNF-5035 detector, developed by German Aaronia with high sensitivity $(1 \mu \mathrm{V})$ in a range of $1-12 \mathrm{~Hz}$ and low sampling time $(5 \mathrm{~ms})$, it was possible to measure these waves. During the months of July and August of 2016, very dry and away from electrical discharges in the region of São José dos Campos, SP, Brazil were made several series of measurements to detect these waves. The positive results of these experimental observations as well as discussions and suggestions are presented in this paper.
\end{abstract}

Key words: Ionosphere, lightning, ELF electromagnetic waves.

\section{Introduction}

The non-ionizing radiation environment of a region has its intensity measured in power $(\mathrm{dBm})$ in milliwatts, Volt $/$ meter $(\mathrm{V} / \mathrm{m})$ (electric field) or Volt V in the case of (electrical potential). These values always vary with the frequency band [1] to be measured. General spectrum analyzers can observe this radiation in a particular frequency range, with continuous monitoring or discrete values of predetermined frequency. In general, analyzers covering the frequency range of 1 $\mathrm{kHz}$ to $26 \mathrm{GHz}$ which are currently available on the international trade in addition to having high costs are used for measurements in laboratories. They are not portable, and do not have sufficient sensitivity to observe radiation intensities in power with less than -90 $\mathrm{dBm}$ values which corresponds to $1 \times 10^{-12} \mathrm{~W}$ of power [2]. These analyzers also require multiple sets of antennas to cover the entire frequency range to be used. The procedures which make much more perform steps

Corresponding author: Inácio Martin, Ph.D., main, researchfields: space physics and geophysics. in any spectral intervaland in chosen location.

The non-ionizing radiations are those which do not produce direct ionization, that is, do not have sufficient energy to strip out electrons from atoms $(<12 \mathrm{eV})$, the means have enough power to dissociate molecules, or, break chemical bonds.

Non-ionizing radiation are always present in the environment [3]. Electromagnetic radiation also consists of waves that propagate through space. These waves can be ionizing or non-ionizing and are formed by composing an electric field (E) and magnetic field (B) which oscillates perpendicular to one another in the simplest case. The direction of propagation corresponds to the energy shift (Poynting vector). These radiations include ultraviolet (near the visible), visible light, infrared, ELF (Extremely Low Frequency), LF (Low Frequency), VHF (Very High Frequency) and microwave. Some of this radiation is an electromagnetic spectrum band called radio frequency $(\mathrm{RF})[4,5]$. The alternating electric current also produces electromagnetic fields around the various conductors and equipment in Brazil. For 
example, the oscillation frequency of the alternating current is $60 \mathrm{~Hz}$ and its harmonics are as $120 \mathrm{~Hz}, 180$ $\mathrm{Hz}$ and $240 \mathrm{~Hz}$. Between $1 \mathrm{~Hz}$ and $40 \mathrm{~Hz}$ (ELF) are naturally Schumann waves determined by the resonances in $7.8 \mathrm{~Hz}, 15.7 \mathrm{~Hz}, 20.0 \mathrm{~Hz}$ and $33.0 \mathrm{~Hz}$. Between 1-12 Hz, according to the recent theoretical work $[6,7]$, waves formed in the ionosphere through HF wave and local ions interactions can exist.

These waves are extremely difficult to measure given the low electric field values (E) and magnetic fields (B) by which they transported $[8,9]$.

\section{Material and Methods}

To collect the measures of non-ionizing radiation from $1 \mathrm{~Hz}$ to $1 \mathrm{MHz}$, the latest equipment purchased from Company Aaronia AG, Germany is used. A Spectran NF-5035 sensor works between the frequency ( $1 \mathrm{~Hz}$ to $1 \mathrm{kHz}$, and $1 \mathrm{kHz}$ to $1 \mathrm{MHz}$ ) with a compact and omnidirectional antenna. The sampling time in the measurements may be chosen from $5 \mathrm{~ms}$ to 3,000 ms. The resolution band width (RBW-Resolution Band Width) may range from $0.3 \mathrm{~Hz}$ to $1 \mathrm{MHz}$. The sensor is fully portable with its own batteries for 8 hours of continuous operation. Specific software provided by Aaronia AG writes the data to files (.ldt) and simultaneously generates graphics on screen display of computer that can save images. All details of the parameter settings and operation of the frequency spectrum analyzer can be found in the above-mentioned manufacturer's website. A laptop PC (Dell Vostro i5) was used for the acquisition and determination of the frequency spectra with the measured data files. Because the system is compact and portable, it is possible to carry out surveys of non-ionizing radiation field at any remote location. Fig. 1 shows the lifting of the electric field $(\mathrm{V} / \mathrm{m})$ environment at ITA campus in São José dos Campos, SP, Brazil.

It is observed in this graph that the electric transmission line on site induces the electric field at 60 $\mathrm{Hz}$ and its harmonic $120 \mathrm{~Hz}$, showing the proper functioning of Spectran NF-5053 sensor.

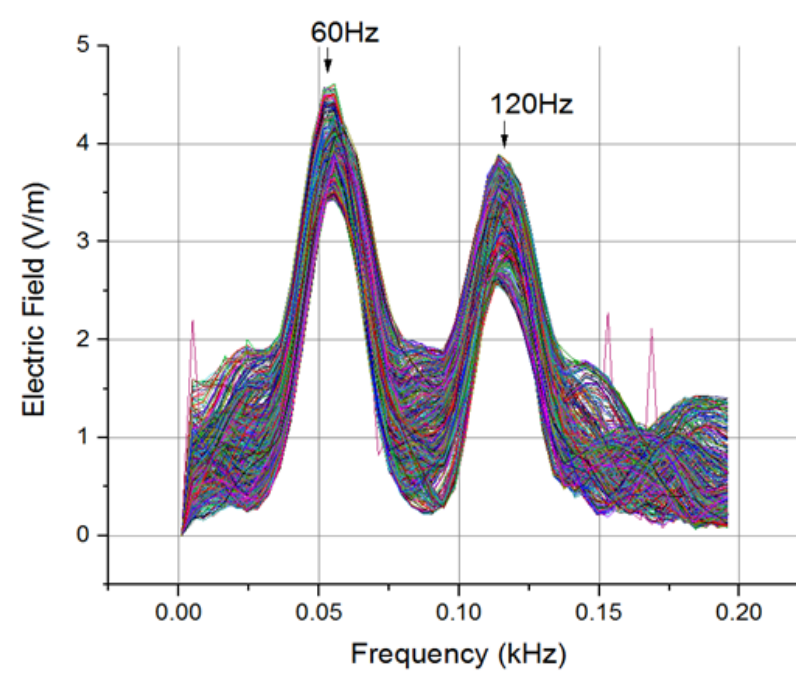

Fig. 1 Measured during 05 minutes of the electric field (V/m) on the campus of the ITA. All the different colors mean number of sampling performed with $60 \mathrm{~Hz}$ and $120 \mathrm{~Hz}$.

\section{Results and Discussion}

The measures in São José dos Campos were made on the campus of the Department of Physics of the ITA (Technological Institute of Aeronautics) without direct interference from the local power grid. As a first result, it was found that the electric field spectrum $(\mathrm{V} / \mathrm{m})$ between $1 \mathrm{~Hz}$ and $16 \mathrm{~Hz}$ was repetitive and constant in region with an intensity of $<2 \mathrm{~V} / \mathrm{m}$. The highest electric potential in $2.2 \mathrm{~Hz}, 4.3 \mathrm{~Hz}, 6.1 \mathrm{~Hz}$ and $7.6 \mathrm{~Hz}$ located peaks, was wavering between 40 and 50 microvolts and background noise with a lower value of 10 microvolts is as shown in Fig. 2 below. To this extent, the electric potential of the local site to that referring is already included local power network that contributes a maximum to 5 microvolts in August and September of 2016. Measures in Fig. 2 made with monitoring obtained on $09 / 06 / 2016$ from 08:49 to 09:40 local time show that the values are already the maximum of the region. Generally nocturnal measures and periods are until 07:00 local time, and the intensity of this wave of $1-12 \mathrm{~Hz}$ is a minimum of 10 microvolts order. From 07:00 local time until 10:00, the wave is oscillating between the minimum to maximum value, as shown in Figs. 3 and 4, of measurements from different days and months. Fig. 5 shows the average 
achieved in 08/11/2016 measures in the afternoon between 15:06 to 15:12 local time.

This average is made in the maximum values whose evidence is very clear in the afternoon (Fig. 6).

\section{Conclusion}

In the period of August to September in 2016, the spectrum in frequency from $1 \mathrm{~Hz}$ to $16 \mathrm{~Hz}$ was measured through a Spectran NF-5035 sensor developed by a German company, Aaronia Ag. This spectrum showed electric potential peaks $(\mathrm{V})$ at $2.2 \mathrm{~Hz}$, $4.3 \mathrm{~Hz}, 6.1 \mathrm{~Hz}$ and $7.6 \mathrm{~Hz}$ ranging from 40 to 50 microvolts maximum in the period from 10:00 to 20:00 local time. At night until 07:00 morning in the local time, this reached near 10 microvolts in the same frequency range. Between 07:00 and 10:00 local time, values are minimum passing unstable $(\sim 10 \mu \mathrm{V})$ to the maximum $(\sim 50 \mu \mathrm{V})$ as shown in Figs. 2, 3 and 4 in the text. It was found that in the morning hours before 10:00 local time, the electric potential of the signal becomes maximum when there is an increase of X-rays flux in wavelength from 0.5 to $4.0 \AA$ and in wavelength from 1 to $8 \AA$; shown by satellite Goes series 13 and 15 measurements. It was concluded that through diamagnetic currents in the ionosphere, it is more or less ionized creating electromagnetic waves between 1 $\mathrm{Hz}$ and $12 \mathrm{~Hz}$, and visible peaks with intensities and frequencies described above.

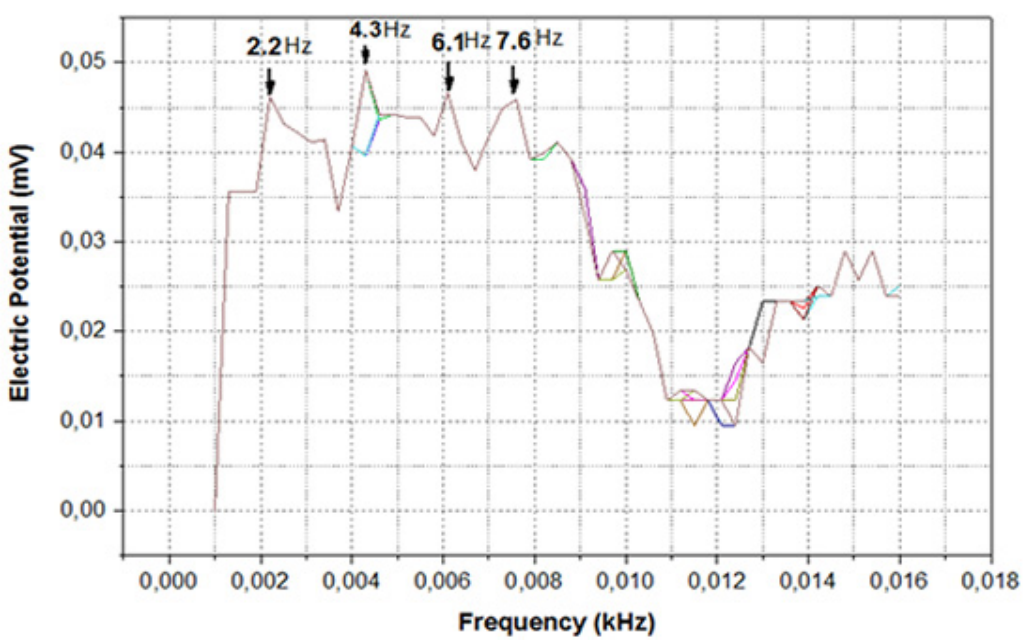

Fig. 2 Measures of electromagnetic waves between (1-12) $\mathrm{Hz}$, highlighting the peaks at 2.2; 4.3; 6.1 $\mathrm{Hz}$ and 7.6 $\mathrm{Hz}$, obtained during 08:49 to 09:49, 06/09/2016 (LT).

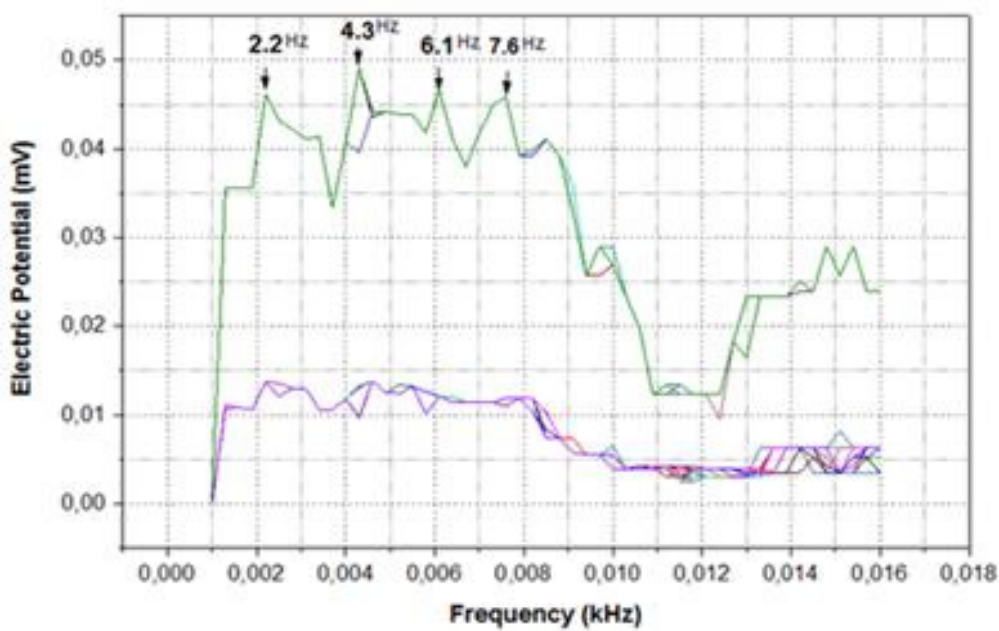

Fig. 3 Measurements of waves between (1-12) $\mathrm{Hz}$ unstable oscillating between maximum and minimum values of electric potential of the day 06/09/2016 between 07:49 to 07:53 (LT). 


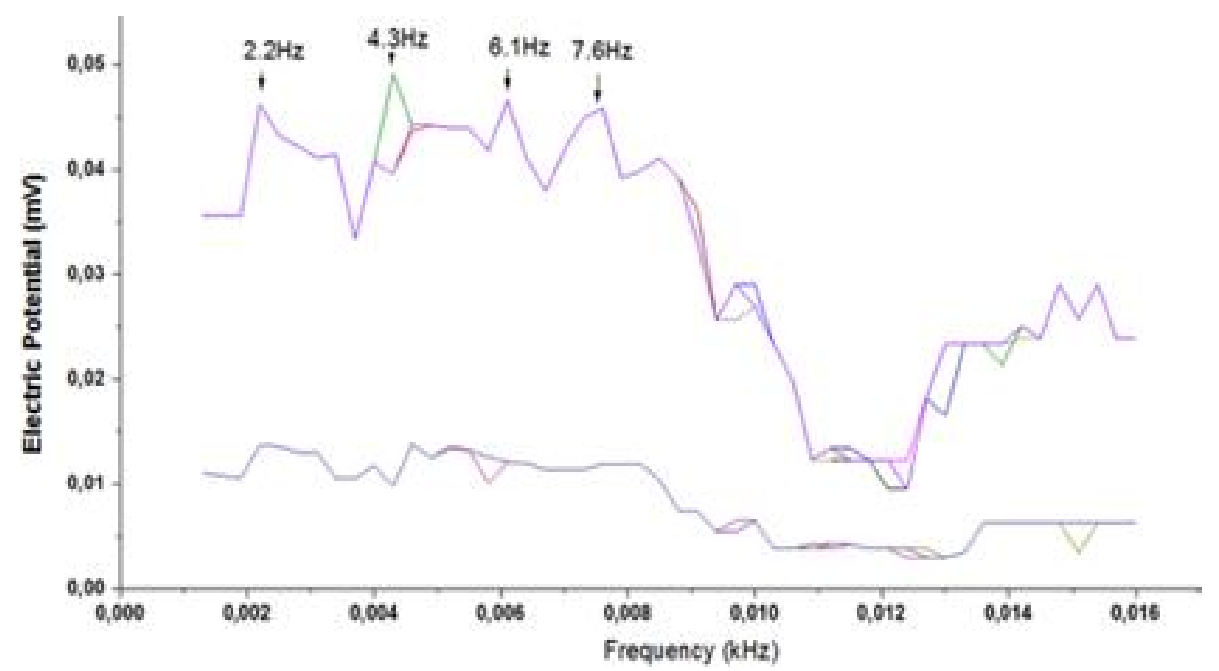

Fig. 4 Measurements of ELF waves between 1-12 Hz performed at 07:26 to 07:30 (LT) on the morning of the day 31/08/2016 showing the instability in ionosphere in this time.

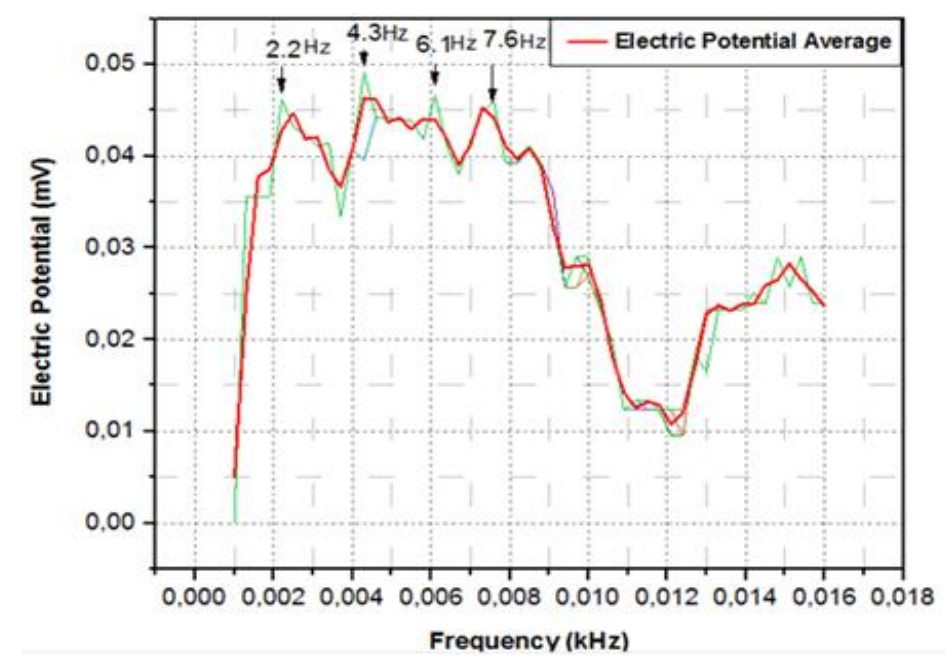

Fig. 5 Measurements of the ELF waves (average value) made in the afternoon between 15:06 to 15:12 (LT) on 11/08/2016 showing only maximum values at this time.

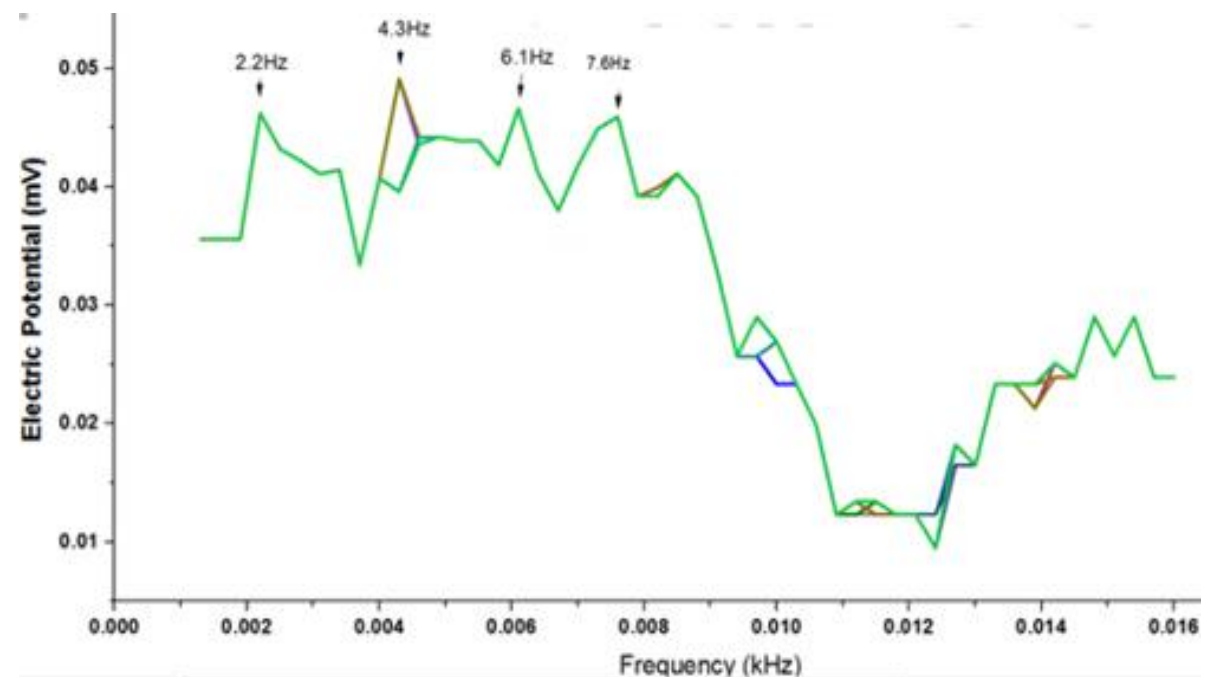

Fig. 6 Measurements of the electric potential $(\mathrm{mV})$ between (1-12) $\mathrm{Hz}$ showing maximum values of $(0.05 \mathrm{mV})$. This image is plotted directly with data tacked by Spectran NF-5035 on 09/12/2016. 


\section{Acknowledgment}

Thanks CNPq (National Counsel of Technological and Scientific Development) and CAPES (Coordination for the Improvement of Higher Education Personnel) by the fellowships grants support to the group's researchers. The ITA Division of Fundamental Sciences for supporting this research.

\section{References}

[1] Martin, I. M., and Marcelo Pêgo Gomes e Mauro Ângelo Alves. 2013. "Medidas dos espectros da radiação não ionizantes de São José dos Campos e Taubaté." Brasil Revista Telecomunicações 15 (1): 7-10.

[2] Rapid Tables. "How to Make the Decibel- $\mathrm{dB}_{\mathrm{m}}$ Conversion on Watts (W)." Online Reference \& Tools Accessed October

2016. www.rapidtables.com/convert/power/Watt_to_dBm.htm.

[3] Gusev, A. A., Martin, I. M., Ferreira, D. V., and Otani, E. C. 2005. "The Shelter of High Energy Electrons Produced by the Powerfull HF Transmitter.” IMOC-2005 (IEEE-USA) Accessed October 2016. http://ieeexplore.ieee. org/stamp/stamp.jsp? arnumber=1580003.

[4] Viega, F. M., and Martin, I. M. 2012. "Medidas da radiação não ionizantes na cidade de São José dos Campos, SP, Brazil.” XII ENCITA-ITA.

[5] AARONIA. 2011. "World's Smallest up to $9,4 \mathrm{GHz}$ Analyser Spectrum.” AARONIA, Accessed October 2016. www.aaronia.de.

[6] Sharma, S., Eliasson, B., Mlikh, G. M., Najmi, A., Papadopoulos, K., Shao, X., et al. 2016. "Low-Frequency Waves in HF Heating of the Ionosphere.” Low-Frequency Waves in Space Plasmas, Geophysical Monograph 216: 31-49.

[7] Cohen, M. B., and Golkowski, M. 2013. "100 Days of ELF/VLF Generation via HF Heating with HAARP.” $J$. Geophys. Res. 118 (A10): 6597-6607.

[8] PRB (Population Reference Bureau). 2002. "Nexos.” PRB Acessed September 2016. http://www.prenatal.tv/lecturas/efectos $\% 20 \mathrm{del} \% 20$ medio $\% 20$ ambiente $\% 20$ en $\% 201 \mathrm{a} \% 20$ salud $\% 20$ infantil.pdf.(in Spanish).

[9] Chand, R., Israil, M., and Rai, J. 2009. "Schumann Resonance Frequency Variations Observed in Magnetotelluric Data Recorded from Garhwal Himalayan Region India.” Annales Geophysicae 27: 3497-3507. 